\title{
Adsorption Properties of Tetracycline onto Graphene Oxide: Equilibrium, Kinetic and Thermodynamic Studies
}

\author{
Ehsan Ezzatpour Ghadim ${ }^{1}$, Firouzeh Manouchehri ${ }^{2}$, Gholamreza Soleimani ${ }^{3}$, Hadi Hosseini ${ }^{4}$, \\ Salimeh Kimiagar ${ }^{3}$, Shohreh Nafisi ${ }^{2 *}$
}

1 Young Researchers and Elite Club, Central Tehran Branch, Islamic Azad University (IAUCTB), Tehran, Iran, 2 Department of Chemistry, Islamic Azad University, Central Tehran Branch (IAUCTB), Tehran, Iran, 3 Department of Physics, Islamic Azad University, Central Tehran Branch (IAUCTB), Tehran, Iran, 4 Department of Chemistry, Shahid Beheshti University, Evin, Tehran, Iran

\begin{abstract}
Graphene oxide (GO) nanoparticle is a high potential effective absorbent. Tetracycline (TC) is a broad-spectrum antibiotic produced, indicated for use against many bacterial infections. In the present research, a systematic study of the adsorption and release process of tetracycline on $\mathrm{GO}$ was performed by varying $\mathrm{pH}$, sorption time and temperature. The results of our studies showed that tetracycline strongly loads on the GO surface via $\pi-\pi$ interaction and cation- $\pi$ bonding. Investigation of TC adsorption kinetics showed that the equilibrium was reached within $15 \mathrm{~min}$ following the pseudo-second-order model with observed rate constants of $k_{2}=0.2742-0.5362 \mathrm{~g} / \mathrm{mg} \mathrm{min}$ (at different temperatures). The sorption data has interpreted by the Langmuir model with the maximum adsorption of $323 \mathrm{mg} / \mathrm{g}(298 \mathrm{~K})$. The mean energy of adsorption was determined $1.83 \mathrm{~kJ} / \mathrm{mol}(298 \mathrm{~K})$ based on the Dubinin-Radushkevich (D-R) adsorption isotherm. Moreover, the thermodynamic parameters such as $\Delta \mathrm{H}^{\circ}, \Delta \mathrm{S}^{\circ}$ and $\Delta \mathrm{G}^{\circ}$ values for the adsorption were estimated which indicated the endothermic and spontaneous nature of the sorption process. The electrochemistry approved an ideal reaction for the adsorption under electrodic process. Simulation of GO and TC was done by LAMMPS. Force studies in z direction showed that tetracycline comes close to $\mathrm{GO}$ sheet by $\mathrm{C}_{8}$ direction. Then it goes far and turns and again comes close from amine group to the GO sheet.
\end{abstract}

Citation: Ghadim EE, Manouchehri F, Soleimani G, Hosseini H, Kimiagar S, et al. (2013) Adsorption Properties of Tetracycline onto Graphene Oxide: Equilibrium, Kinetic and Thermodynamic Studies. PLoS ONE 8(11): e79254. doi:10.1371/journal.pone.0079254

Editor: Heidar-Ali Tajmir-Riahi, University of Quebect at Trois-Rivieres, Canada

Received August 14, 2013; Accepted September 20, 2013; Published November 26, 2013

Copyright: (c) 2013 Ghadim et al. This is an open-access article distributed under the terms of the Creative Commons Attribution License, which permits unrestricted use, distribution, and reproduction in any medium, provided the original author and source are credited.

Funding: This work is supported by Azad University, Central Tehran Branch (IAUCTB). The funders had no role in study design, data collection and analysis, decision to publish, or preparation of the manuscript.

Competing Interests: The authors have declared that no competing interests exist.

*E-mail: drshnafisi@gmail.com

\section{Introduction}

Graphene oxide (GO) (Fig. 1a), a derivative of graphene, is a non-toxic and more biocompatible than other existing nanoparticles, such as quantum dots, noble metals (gold/silver nanoparticles), and rare-earth ions (upconversion nanocrystals) [1]. It is a $\mathrm{sp}^{2}$-bonded carbon sheets with individual physical and chemical properties which has attracted remarkable attention since 2004 [2]. Many researches have explored the potential of GO for variety biomedical applications such as electrochemical devices $[3,4]$, energy storage [5,6], catalysis [7], adsorption of enzyme, cell imaging and drug delivery, as well as biosensors. Most of the antibiotic drugs like TC have appropriate interaction with GO via $\pi-\pi$ stacking $[8,9]$. Large quantities of oxygen atoms in the forms of epoxy, hydroxyl, carboxyl groups and delocalized conjugated $\pi$ electrons on the surface of the GO [5] builds it extremely hydrophilic and provides the capability to apply GO in the aquatic and biological environment.

Tetracycline (TC, $\mathrm{C}_{22} \mathrm{H}_{24} \mathrm{~N}_{2} \mathrm{O}_{8}$ ) (Fig. lb) is the second greatest antibiotic which is extensively used in the world. It exhibits broadspectrum antimicrobial activity against a variety of diseases. Tetracyclines are pluripotent drugs that inhibit the activity of matrix metalloproteinases (MMPs) and affect many cellular functions including proliferation, migration, and matrix remodel- ing [10]. TC has a planar structure consisting of four fused rings with hydrophilic groups on one face, hydrophobic groups on the other face and each ring including phenol, alcohol, ketone and amino.

Controlling delivery systems are used to improve therapeutic efficacy and safety of drugs by delivering them at a rate dictated which is needed due to the physiological environment during a period of treatment to the site of action [11]. Many problems are minimized when the drug release process is slow [12]. New drug delivery vehicles such as liposomes, dendrimers and graphene oxide nanoparticles offer a promising way to improve bioavailability, efficacy and specificity of pharmaceutical compounds in general [13].

In the present work, GO was prepared and used as an adsorbent to deal with tetracycline at different $\mathrm{pHs}$, sorption times and concentrations. Free Gibbs energy, enthalpy, entropy, and activation energy due to pseudo first and second order equations were calculated. The adsorption kinetics, isotherms and thermodynamics of TC on GO were systematically approved the $\pi-\pi$ interaction mechanism between them. The mechanism for adsorption of tetracycline on GO was deduced from fitting adsorption isotherms. In order to study the behavior of TC on GO surface, simulation of GO and TG was done by LAMMPS. 

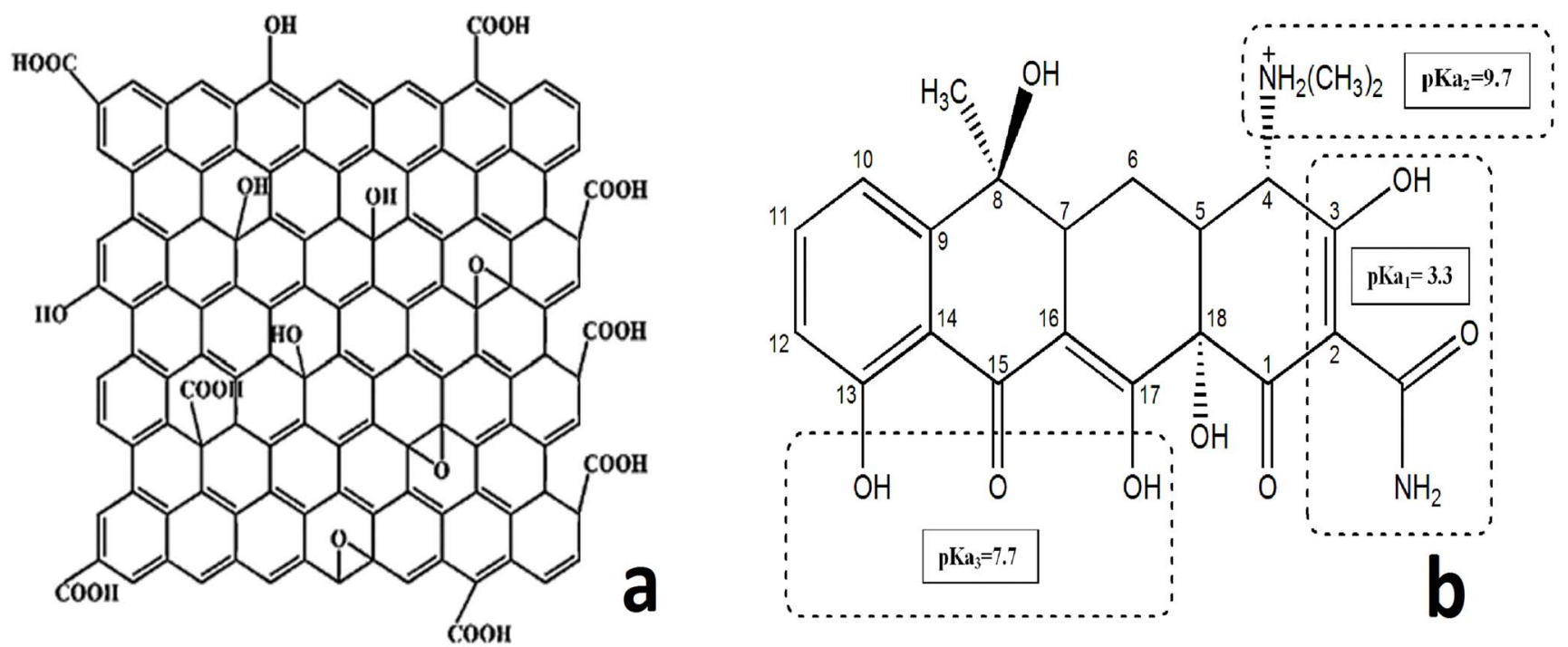

Figure 1. Structure of graphene oxide (a), Structure of tetracycline and pKa values (b). doi:10.1371/journal.pone.0079254.g001

\section{Materials and Methods}

\section{Materials}

Tetracycline hydrochloride, graphite flakes (150 $\mu \mathrm{m}$ flakes) were purchased from Sigma-Aldrich chemical Co. USA. GO nanoparticles were manufactured by improved Hummers method [14]. Other chemicals used were of analytical reagent grade and used without further purification.

\section{FTIR Spectroscopy}

Infrared spectra were recorded on a FTIR spectrometer (100 N model), equipped with deuterated triglycine sulphate (DTGS) detector and $\mathrm{KBr}$ beam splitter, using $\mathrm{AgBr}$ windows. Solution of TC $(4 \mathrm{~g} / \mathrm{L})$ was added dropwise to the GO $(4 \mathrm{~g} / \mathrm{L})$ solution and mixed thoroughly by a vortex mixer. The suspension was incubated at $25^{\circ} \mathrm{C}$ overnight and wrapped in aluminum foil to avoid possible photodegradation of tetracycline. The suspension

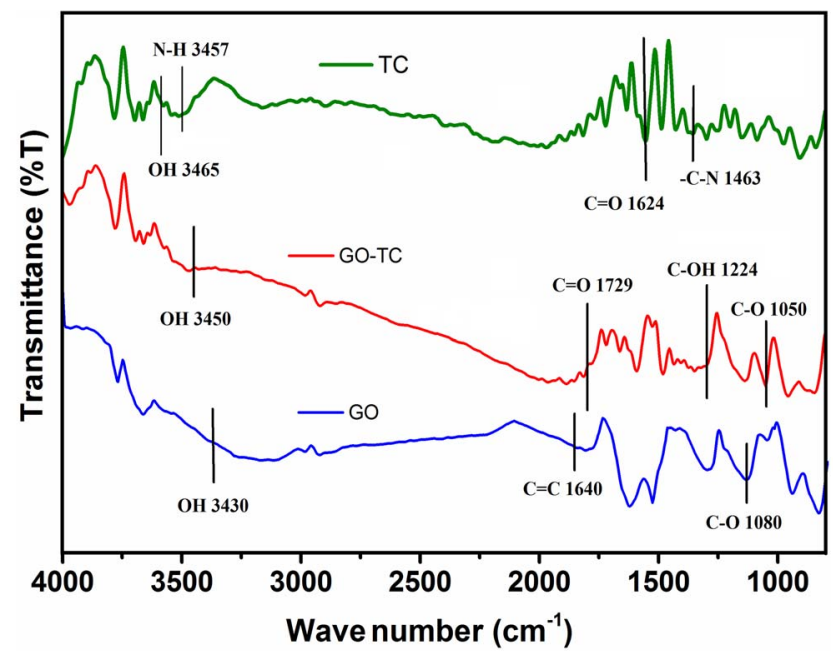

Figure 2. FTIR spectra of free $T C$, free $G O$ and $T C$ after adsorption on GO (GO-TC).

doi:10.1371/journal.pone.0079254.g002 was centrifuged at $12000 \mathrm{rpm}$ for $15 \mathrm{~min}$. The supernatant was collected for FTIR measurements using hydrated films [15]. Interferograms were accumulated over the spectral range 4000$600 \mathrm{~cm}^{-1}$ with a nominal resolution of $4 \mathrm{~cm}^{-1}$ and 100 scans.

\section{UV-Visible Spectroscopy}

The UV-Vis spectra were recorded on a Perkin-Elmer Lambda spectrophotometer with a slit of $2 \mathrm{~nm}$ and scan speed of $400 \mathrm{~nm} /$ min. Quartz cuvettes of $1 \mathrm{~cm}$ were used. The absorbance assessments were performed at $\mathrm{pH} 7.0$ by concentration of $\mathrm{GO}$ (20 mg/L), TC (100 mg/L) and GO-TC.

\section{Voltammetric Experiments}

Voltammetric experiments were performed using a $\mu$ Autolab Type III electrochemical system. A conventional three-electrode cell consisting of a glassy carbon working electrode (modified and unmodified), a platinum wire counter electrode and a saturated $\mathrm{Ag} / \mathrm{AgCl}$ reference electrode were used. Glassy carbon electrode (GCE) was cleaned by polishing with $0.05 \mu \mathrm{m}$ alumina slurry on a polishing cloth to create a mirror finish; the electrode was then rinsed thoroughly with double-distilled water and then dried under ambient temperature. Typically, a stable suspension of graphene oxide containing $2.0 \mathrm{mg} / \mathrm{ml}$ in DMF using $30 \mathrm{~min}$ ultrasonic agitation was prepared. After the electrode surface was air dried, $5.0 \mu \mathrm{L}$ of this suspension was cast onto the surface of the pretreated GC electrode by a micro syringe and then it was dried in air.

\section{General Adsorption Experiments}

To demonstrate the release efficiency directly, the adsorption experiments were performed using a series of $50 \mathrm{~mL}$ flasks containing $20 \mathrm{mg} / \mathrm{L}$ GO and $25 \mathrm{~mL}(6-180 \mathrm{mg} / \mathrm{L})$ TG solutions. The $\mathrm{pH}$ of the solutions were adjusted to $6-7$ by adding $\mathrm{HCl}$ or $\mathrm{NaOH}$. The mixtures of $\mathrm{GO}$ and $\mathrm{TC}$ solutions were incubated overnight and used for determination by UV-Vis absorbance at $356 \mathrm{~nm}$

To deliberation the influence of $\mathrm{pH}$ on adsorption, the mixtures of GO (2 $\mathrm{ml}$ of $20 \mathrm{mg} / \mathrm{L}$ ) and TC solutions (4 ml of 10-100 mg/ $\mathrm{L})$ were prepared. The $\mathrm{pH}$ of solutions were adjusted from 2 to 10 using $\mathrm{NaOH}$ and $\mathrm{HCl}$ and incubated overnight. The supernatant 


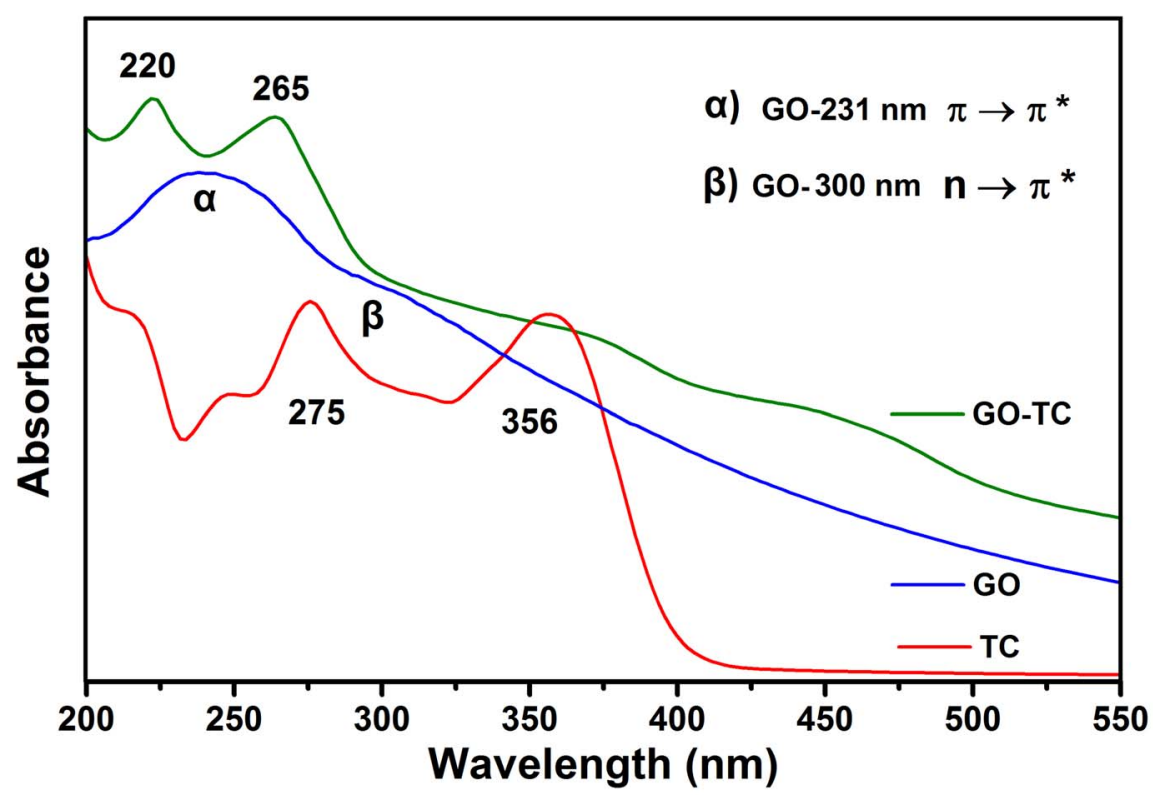

Figure 3. The UV-Vis absorption spectra of free TC, free GO and TC after adsorption on GO (GO-TC). doi:10.1371/journal.pone.0079254.g003

was collected for determination by UV-Vis absorbance at $356 \mathrm{~nm}$. The adsorption percentage (Ads. \%) was calculated based on the equation (1) :

$$
A d s . \%=\frac{C_{0}-C_{e}}{C_{e}} \times 100
$$

$\mathrm{C}_{0}$ and $\mathrm{C}_{\mathrm{e}}$ are the initial and the equilibrium concentrations of $\mathrm{TC}$ in solution phase, respectively.

To investigate the kinetics of the adsorption, $2 \mathrm{~mL} \mathrm{GO}(20 \mathrm{mg}$ / $\mathrm{L})$ was mixed with $4 \mathrm{~mL}$ of different concentrations of tetracycline $(6-180 \mathrm{mg} / \mathrm{L})(\mathrm{pH}=3.6)$. The mixtures were taken for centrifugation with 15 min interval after vigorous mixing by vortex

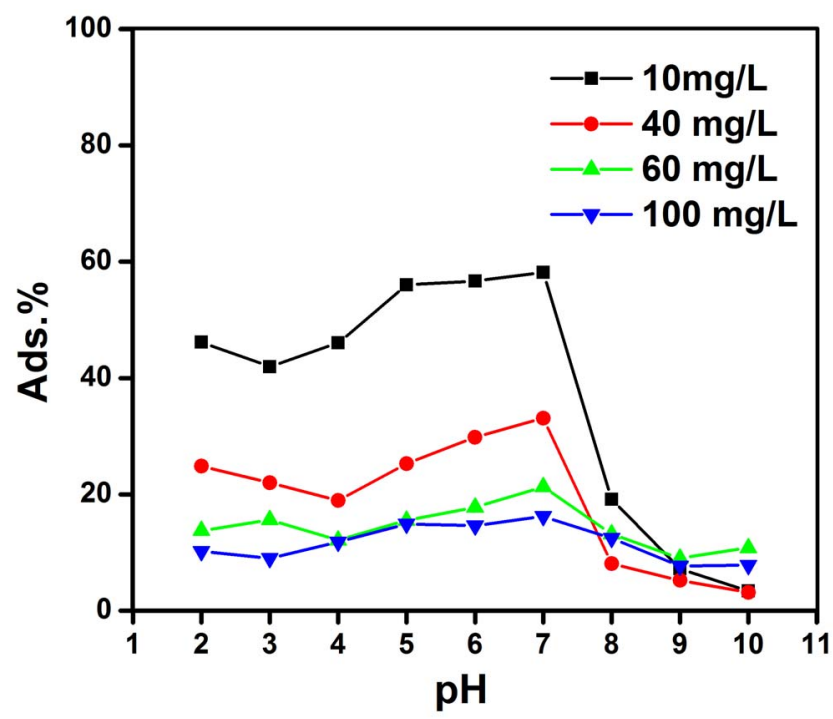

Figure 4. Effect of $\mathrm{pH}$ on the adsorption efficiency of TC (10.0$100.0 \mathrm{mg} / \mathrm{L})$ on GO (20.0 mg/L); Temp. $25 \pm 0.1$.

doi:10.1371/journal.pone.0079254.g004 mixture. On regular time intervals, the concentrations of tetracycline in supernatant were determined successively by UVVis absorbance at $356 \mathrm{~nm}$. The rate constants were calculated using the conventional rate expression.

The effect of temperature on the sorption of tetracycline by GO was estimated by incubating the samples ( $2 \mathrm{ml} \mathrm{GO} 20 \mathrm{mg} / \mathrm{L})$ and $4 \mathrm{~mL}$ of different concentrations of tetracycline $(6-180 \mathrm{mg} / \mathrm{L})$ overnight and then beneath different temperatures $(298,308$, and $318 \mathrm{~K})$. The temperature was preserved through the procedure of investigation including under centrifugation. The supernatant was collected for determination by UV-Vis absorbance at $356 \mathrm{~nm}$.

Adsorption isotherm studies were carried out with constant concentration of GO $(20 \mathrm{mg} / \mathrm{L})$ and different concentrations of tetracycline solutions $(6-180 \mathrm{mg} / \mathrm{L}), \mathrm{pH}=3.6$ and different temperatures; 298, 303 and $308 \mathrm{~K}$ [16]. GO solutions were incubated with tetracycline overnight and covered by aluminum foil to refraining probable photo degradation of tetracycline [17]. Then suspension was centrifuged at $6000 \mathrm{rpm}$ for $30 \mathrm{~min}$. The supernatant was gathered for determination by UV-Vis absorbance at $356 \mathrm{~nm}$, drawing a calibration curve manufactured with tetracycline solutions of different concentrations. The absorption experiments were performed under the same condition, but different temperatures (298, 303 and $308 \mathrm{~K})$.

\section{Simulation}

LAMMPS (Large-scale Atomic/Molecular Massively Parallel Simulator) is a classical molecular dynamics code that models an ensemble of particles in a liquid, solid, or gaseous state. It can model atomic, polymeric, biological, metallic, granular, and coarse-grained systems using a variety of force fields and boundary conditions. In the most general sense, LAMMPS integrates Newton's equations of motion for collections of atoms, molecules, or macroscopic particles that interact via short- or long-range forces with a variety of initial and/or boundary conditions. For computational efficiency, LAMMPS uses neighbor lists to keep track of nearby particles. The lists are optimized for systems with particles that are repulsive at short distances, so that the local density of particles never becomes too large. 

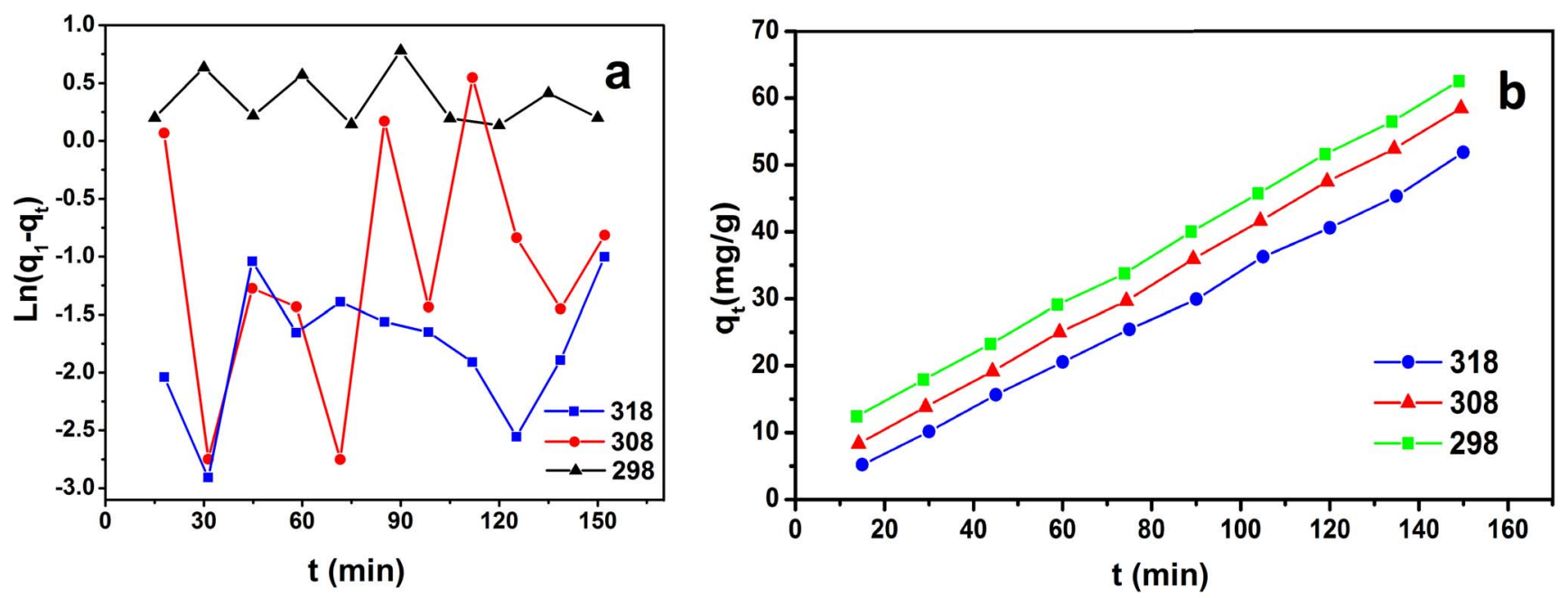

Figure 5. The pseudo-first-order (a) and the pseudo-second-order (b) kinetics model for adsorption of tetracycline on Go suspension $(20.0 \mathrm{mg} / \mathrm{L}), \mathrm{pH}=3.6, \mathrm{~T}=298,308,318 \mathrm{~K}$. doi:10.1371/journal.pone.0079254.g005

In the present research, we used adaptive intermolecular reactive bond order (AIREBO) potential using numerical. Both the repulsive and attractive pair interaction functions are modified to fit bond properties. Long range atomic interactions and single bond torsional interactions are also included [18,19].

\section{Results}

\section{Adsorption of Tetracyclines by Graphene Oxide Suspension}

FT-IR and UV-Vis spectroscopy were employed to investigate the adsorption of tetracycline on GO.

\section{FTIR Spectral Analysis of Tetracycline-graphene Oxide}

Transform Infrared (FTIR) spectra of TC showed apparent characteristic bands at $3465 \mathrm{~cm}^{-1}(\mathrm{O}-\mathrm{H}), 3457,3441 \mathrm{~cm}^{-1}(\mathrm{~N}-$ $\mathrm{H}), 1624 \mathrm{~cm}^{-1}(\mathrm{C}=\mathrm{O})$ and $1463 \mathrm{~cm}^{-1}(=\mathrm{C}-\mathrm{N})$ (Fig. 2). In GOTC complex, shifting of the TC absorption bands to $3450 \mathrm{~cm}^{-1}$ $(\mathrm{O}-\mathrm{H}), 1729 \mathrm{~cm}^{-1}(\mathrm{C}=\mathrm{O})$, and appearance of the new bands at $1224 \mathrm{~cm}^{-1}(\mathrm{C}-\mathrm{OH})$, and $1050 \mathrm{~cm}^{-1}(\mathrm{C}-\mathrm{O})$, suggesting that oxygen-containing groups are introduced into the graphene structure (Fig. 2). Go and TC stick to each other and form bundles, and the space between the bundles provides more adsorption sites [20]. Water molecules could form H-bands with functional groups on GO, which blocks the access of TC molecules into the sorption sites.

Table 1. Kinetic parameters for $\mathrm{TC}$ adsorption on $\mathrm{GO}$ at different temperatures.

\begin{tabular}{|c|c|c|c|c|}
\hline \multirow[b]{2}{*}{$\mathbf{T}(\mathbf{K})$} & \multicolumn{4}{|c|}{ Pseudo-second-order model } \\
\hline & $k_{2}(1 / \mathrm{min})$ & $q^{2}(m g / g)$ & h (mg/g min) & $r^{2}$ \\
\hline 298 & 0.3468 & 198.54 & 68.89 & 0.996 \\
\hline $\mid 308$ & 0.2742 & 381.77 & 104.7 & 0.994 \\
\hline 318 & 0.5362 & 411.76 & 221.8 & 0.986 \\
\hline
\end{tabular}

\section{UV-Visible Spectra}

The absorption spectra of GO, tetracycline, and GO-TC are shown in Fig. 3. The GO dispersion displays a maximum absorption at $231 \mathrm{~nm}$, which is due to the $\pi-\pi^{*}$ transition of aromatic $\mathrm{C}=\mathrm{C}$ bands (Fig. 3). Furthermore, a similar shoulder band around $\sim 300 \mathrm{~nm}$ is observed which can be attributed to $\mathrm{n} \rightarrow \pi^{*}$ transitions of the carbonyl groups [21]. The TC absorption bands are located at 356 and $275 \mathrm{~nm}$ which blue shifted and appeared at 265 and $220 \mathrm{~nm}$ upon adsorption on GO. The adsorption process is possibly the non-electrostatic-dispersion interaction between bulk systems on GO surface and TC molecules contained both benzene rings and double bands $(\mathrm{C}=\mathrm{C}, \mathrm{G}=\mathrm{O})$, or hydrophobic and $\pi-\pi$ electron donor-accepter interaction between GO and TC. The cation $-\pi$ bonding may happen between the easily protonated amino group which is on the ring $\mathrm{C}_{4}$ of the tetracycline molecule and the graphene

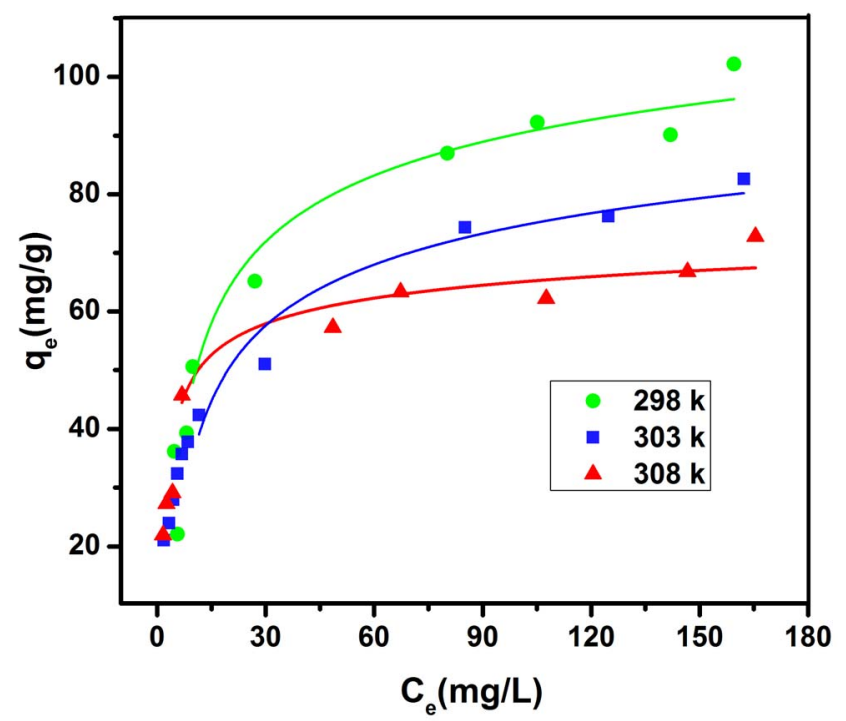

Figure 6. Isotherm of TC (6.0-180.0 mg/L) adsorption on GO $(20.0 \mathrm{mg} / \mathrm{L})$ at different temperatures $(298,303,308 \mathrm{~K})$. doi:10.1371/journal.pone.0079254.g006 
Table 2. Langmuir, Freundlich and D-R constants and correlation coefficients of TC adsorption on GO at different temperatures.

\begin{tabular}{|c|c|c|c|c|c|c|c|c|c|}
\hline \multirow[b]{2}{*}{$\mathbf{T}(\mathrm{K})$} & \multicolumn{3}{|l|}{ Langmuir } & \multicolumn{3}{|l|}{ Freundlich } & \multicolumn{3}{|l|}{$\mathbf{D}-\mathbf{R}^{*}$} \\
\hline & $q_{m}(m g / g)$ & $\mathbf{R}_{\mathbf{L}}$ & $r^{2}$ & $\mathrm{~K}_{\mathrm{F}}(\mathrm{mg} / \mathrm{g})$ & n & $r^{2}$ & $q_{m}(\mathrm{mg} / \mathrm{g})$ & $E(\mathbf{k j} / \mathrm{mol})$ & $r^{2}$ \\
\hline 298 & $322.43 \pm 1.25$ & 0.01787 & 0.997 & 21.40 & 3.656 & 0.943 & $24.62 \pm 0.74$ & 1.83 & 0.961 \\
\hline 303 & $101.87 \pm 1.08$ & 0.00846 & 0.993 & 20.09 & 3.762 & 0.962 & $22.92 \pm 0.59$ & 1.69 & 0.988 \\
\hline 308 & $73.53 \pm 0.55$ & 0.2546 & 0.998 & 20.13 & 3.721 & 0.983 & $24.94 \pm 0.61$ & 1.40 & 0.988 \\
\hline
\end{tabular}

${ }^{*}$ Dubinin-Radushkevich.

doi:10.1371/journal.pone.0079254.t002

$\pi$-electrons. Similar interactions are observed in graphite and carbon nanotubes [9,22].

\section{Effect of $\mathrm{pH}$}

In the present research, different concentrations of TC $(6.0-$ $180.0 \mathrm{mg} / \mathrm{L}$ ) were applied to examine the sorption behavior of TC on a constant concentration of GO (2 ml of $20 \mathrm{mg} / \mathrm{L})$ at different $\mathrm{pH}$ values (2-10 with an interval 1 unit) using UV-Vis spectroscopy. The adsorption percentage (Ads. \%) was calculated based on the equation (1).

It should be noted that tetracycline has variable charges on different sites depending on solution $\mathrm{pH}$. When $\mathrm{pH}$ is under 4, TC exists as a cation $\left(\mathrm{TCH}^{3+}\right)$, due to the protonation of dimethylammonium group. At $\mathrm{pH}$ between 3.5 and 7.5, TC exists as a zwitterion $\left(\mathrm{TCH}_{2}{ }^{0}\right)$, due to the loss of a proton from the phenolic diketone moiety. At $\mathrm{pH}$ upper than 7, TC exists as anion $\left(\mathrm{TCH}^{-}\right.$ or $\mathrm{TC}^{2-}$ ) due to the loss of protons from the tri-carbonyl system and phenolic di-ketone moiety [23]. By increasing the $\mathrm{pH}$ from 4 to 7 , the adsorption of $\mathrm{TC}$ on GO increases (Fig. 4). The maximum adsorption occurs at $\mathrm{pH}$ 7. At $\mathrm{pH}$ higher than 7, the adsorption percentages decreases. For concentrations less than $40 \mathrm{mg} / \mathrm{L}$, the adsorption percentage was found to be above $50 \%$ (pH 5-7). The variation in $\mathrm{pH}$ can not only focuses on the protonation-deprotonating transition of functional groups on $\mathrm{GO}$, but also results in a change in chemical speciation for ionizable organic compounds. The above results are comparable with biological systems in which the $\mathrm{pH}$ inside the cell is 5 and out of cell is 7. This phenomena sufficiently approves that $\mathrm{pH}$ affects absorption of TC on GO and can be used to predict the TC release from GO inside the cells. The above results show that GO can act as an appropriate carrier for drug delivery systems.

\section{Adsorption Kinetics}

In order to investigate the adsorption process of TC on GO, pseudo-first-order and pseudo-second-order kinetics model were used.

Pseudo-first-order model:

Table 3. Thermodynamic parameters for the adsorption of TC on GO.

\begin{tabular}{|c|c|c|c|c|c|}
\hline \multirow[b]{2}{*}{$C_{0}(\mathrm{mg} / \mathrm{L})$} & \multirow{2}{*}{$\begin{array}{l}\Delta \mathbf{H}^{\circ}(\mathbf{k J} / \\
\mathrm{mol})\end{array}$} & \multirow{2}{*}{$\begin{array}{l}\Delta \mathbf{S}^{\circ}(\mathbf{k J} / \\
\mathrm{mol} \mathbf{K})\end{array}$} & \multicolumn{3}{|c|}{$\Delta \mathrm{G}^{\circ}(\mathrm{kJ} / \mathrm{mol})$} \\
\hline & & & 298 K & $303 \mathrm{~K}$ & 308 K \\
\hline 20.0 & 44.045 & 0.2553 & -2.0068 & -3.2704 & -2.1731 \\
\hline
\end{tabular}

The pseudo-first-order equation is given as Eq. (2) [16,20,24]:

$$
\operatorname{Ln}\left(q_{1}-q_{t}\right)=\ln q_{1}-k_{1} t
$$

Where $\mathrm{q}_{1}$ and $\mathrm{q}_{\mathrm{t}}$ are the amount of $\mathrm{TC}$ adsorbed on the sorbent $(\mathrm{mg} / \mathrm{g})$ at equilibrium and at time $\mathrm{t}$, respectively, and $\mathrm{k}_{1}$ is the rate constant of the first-order adsorption $\left(\mathrm{min}^{-1}\right)$. The values $\mathrm{k}_{1}$ for $\mathrm{TC}$ adsorption on GO were defined from the plot of $\mathrm{Ln}\left(\mathrm{q}_{1}-\mathrm{q}_{\mathrm{t}}\right)$ against t (Fig. 5a).

Pseudo-second-order model:

The pseudo-second-order model is represented as Eq. (3) [25]:

$$
\frac{t}{q_{t}}=\frac{1}{k_{2} q_{2}^{2}}+\frac{t}{q_{2}}
$$

Where $\mathrm{k}_{2}$ is the rate constant of the second-order adsorption ( $\mathrm{g} /$ $\mathrm{mg}$ min). The straight-line plots of $\mathrm{q}_{\mathrm{t}}$ versus $\mathrm{t}$ (Fig. 5b) have been tested to obtain rate parameters. The second-order rate constants were used to calculate the initial sorption rate $\mathrm{h}(\mathrm{mg} / \mathrm{g} \mathrm{min})$ [26], given by:

$$
h=k_{2} q_{2}^{2}
$$

The batch kinetic data based on our investigation were appropriately satisfying the condition of second-pseudo order models. In the present study, Ho's pseudo-second-order kinetics model was exploited to examine the fitness of the experimental data and to evaluate the kinetics of the adsorption of tetracycline on GO. The pseudo-second-order kinetics model was based on the hypothesis that the rate-limiting step includes chemisorption, which has been extensively applied to the sorption of contaminants from aqueous solutions in recent years [27]. So, only secondpseudo order models effectively describe the kinetic data at $95 \%$ confidence level. The consequences of the kinetic parameters and the calculated initial sorption rate values are recorded in Table 1. Based on the correlation coefficients, the adsorption of TC is finest described by the pseudo-second-order model. In an assumed adsorption system, the initial adsorption rate intensified by increasing the temperature. Furthermore, it was probable to calculate the activation energy $\left(\mathrm{E}_{\mathrm{a}}\right)$ for the adsorption employing the Arrhenius equation [28] based on the $\mathrm{k}$ values.

$$
k=A \exp \left(-\frac{E a}{R T}\right)
$$

Where $\mathrm{A}$ is the frequency factor $\left(\mathrm{min}^{-1}\right), \mathrm{E}_{\mathrm{a}}$ is the activation energy $(\mathrm{kJ} / \mathrm{mol}), \mathrm{R}$ is the ideal gas constant $(\mathrm{kJ} / \mathrm{mol} \mathrm{K})$, and $\mathrm{T}$ is the temperature $(\mathbf{K})$ [29]. 

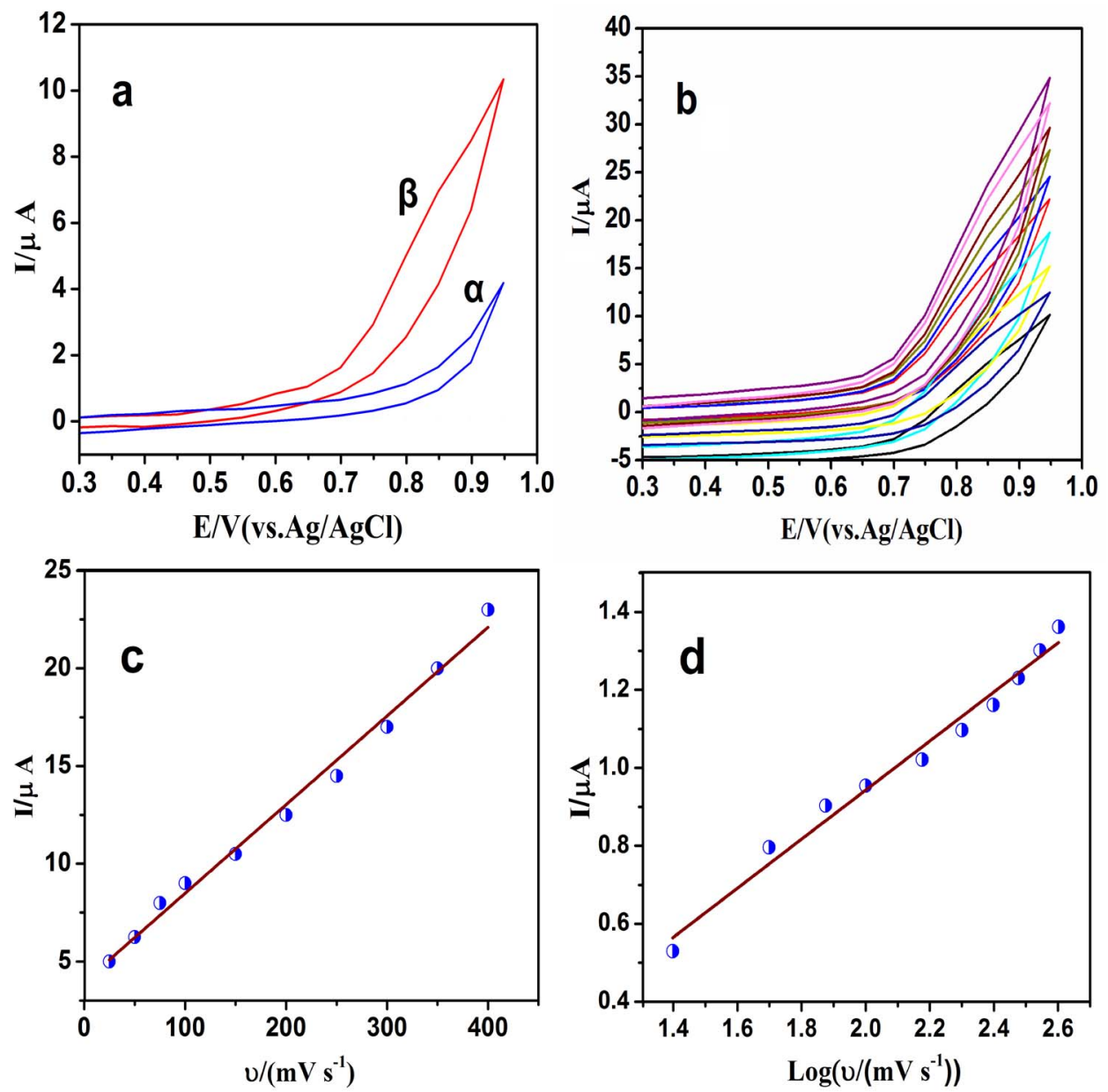

Figure 7. CV curve of tetracycline ( $1 \mathrm{mM}$, in phosphate buffer solution, $0.1 \mathrm{M}, \mathrm{pH}=7$ ) at $50 \mathrm{mV} / \mathrm{s}$ (a); CV curve of tetracycline $(1 \mathrm{mM}$ ) at different scan rates: (from Bottom to up) 25, 50, 75, 100, 150, 200, 250, 300, 350, $400 \mathrm{mV} / \mathrm{s}$ (b); Observed dependence of peak current on the scan rate (c); Plot of variation of peak current with the logarithm of scan rate (d).

doi:10.1371/journal.pone.0079254.g007

Eq. (5) can be converted into Eq. (6) by taking logarithm:

$$
\operatorname{Ln} k=\ln A-E a / R T
$$

Thus, $\mathrm{E}_{\mathrm{a}}$ could be obtained from the slope of the line plotting $\mathrm{ln}$ $\mathrm{k}$ versus $1000 / \mathrm{T}$, the estimated $\mathrm{E}_{\mathrm{a}}$ for $\mathrm{TC}$ adsorption on $\mathrm{GO}$ was $3.2411 \mathrm{~kJ} / \mathrm{mol}$. The lower the $\mathrm{E}_{\mathrm{a}}$ was, the fewer sensitive the temperature effected on the adsorption reaction. It has been proved that the process can be simply conducted.

\section{Adsorption Isotherms}

Adsorption isotherms describe how solutes interact with sorbents. Adsorption isotherms and the equilibrium adsorption amount of TC on GO as a function of equilibrium concentration of TC is depicted in Fig. 6. The absorption data were fitted to both Langmuir and Freundlich model which are often described by equilibrium sorption isotherms model [30]:

$$
\frac{C_{e}}{q_{e}}=\frac{C_{e}}{q_{m}}+\frac{1}{b q_{m}}
$$

Where $\mathrm{C}_{\mathrm{e}}$ is the equilibrium concentration of $\mathrm{TC}(\mathrm{mg} / \mathrm{L}), \mathrm{q}_{\mathrm{m}}$ is the maximum monolayer adsorption $(\mathrm{mg} / \mathrm{g}), \mathrm{q}_{\mathrm{e}}$ is the amount of TC adsorbed per unit weight of GO at equilibrium concentration $(\mathrm{mg} / \mathrm{g})$ and $\mathrm{b}$ is the Langmuir constant related to the affinity of binding sites $(\mathrm{L} / \mathrm{mg})$. The equilibrium concentration $\left(\mathrm{C}_{\mathrm{e}}\right)$ of $\mathrm{TC}$ was calculated mentioning to the calibration curve of TC [31]. Moreover, the widely used empirical Freundlich equation basis on sorption on a heterogeneous surface is given by [32]:

$$
\operatorname{Lg} q_{e}=\lg K_{F}+\frac{1}{n} \lg C_{e}
$$

where $\mathrm{KF}$ and $\mathrm{n}$ are Freundlich constants indicating the sorption capacity $(\mathrm{mg} / \mathrm{g})$ and intensity, respectively. The LangmuirFreundlich isotherm constants were determined from the plots of $\mathrm{Ce} / \mathrm{qe}$ against $\mathrm{Ce}$, lg qe versus $\mathrm{lg}$ Ce, respectively, at 298, 303, 308,310 and $313 \mathrm{~K}$. The isothermal constants and the correlation coefficients are depicted in Table 2. Langmuir and Freundlich isotherm models were statistically important at a $95 \%$ confidence level. It is found that the adsorption of TC on GO correlated well $(r>0.99)$ with the Langmuir equation as compared to the Freundlich equation $(r>0.95)$ underneath the studied concentration range. Therefore, the Langmuir isotherm fits appropriate compared with the Freundlich isotherm in all conditions according to the correlation coefficients $r$. The maximum adsorption 


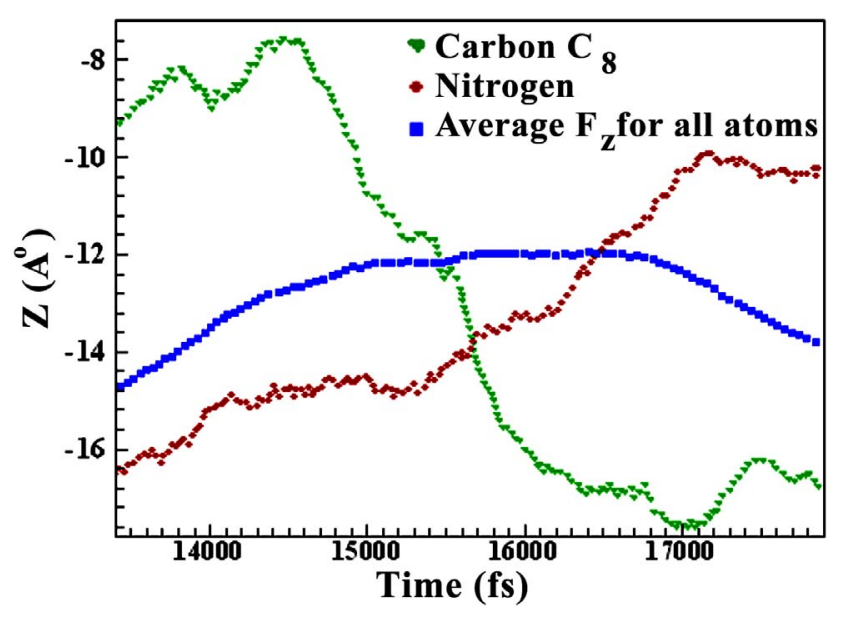

Figure 8. Variation of $z$ vs. time for $C_{8}$ (triangle symbol) and amino (circle symbol). Square symbol is $z$ average over all TC molecules.

doi:10.1371/journal.pone.0079254.g008

capacity of TC on GO was 322.43, 101.87, $73.53 \mathrm{mg} / \mathrm{g}$ at 298 , 303, 308 respectively. The shape of the isotherm has been discussed in order to predict whether an adsorption system is desirable or undesirable. The vital property of the Langmuir isotherms can be expressed by means of 'RL', a dimensionless constant related to the separation factor or equilibrium parameter. $\mathrm{RL}$ is computed using the following equation [25,31]:

$$
R_{L}=\frac{1}{1+b C_{0}}
$$

Where, $\mathrm{C}_{0}$ is the initial TC concentration $(\mathrm{mg} / \mathrm{L})$ and $\mathrm{b}$ is the Langmuir adsorption of equilibrium constant $(\mathrm{L} / \mathrm{mg})$. The calculated $\mathrm{R}_{\mathrm{L}}$ values are recorded in Table 2 . In the present investigation, the equilibrium parameter $R_{L}$ was found to be between 0 and 1 , hence the sorption process was quite favorable and the adsorbent employed demonstrated a good potential for the sorption of TC. Finally, the Dubinin-Radushkevich (D-R) isotherm was also examined in its linearized form:

$$
\operatorname{Ln} q_{e}=\ln q_{m}-K \varepsilon^{2}
$$

Where $\mathrm{q}_{\mathrm{e}}$ and $\mathrm{q}_{\mathrm{m}}$ have the same meaning as above, $\mathrm{K}$ is the parameter linked to the adsorption energy. $\varepsilon$ is the adsorption potential, explained the Polanyi as the free energy change needed to transfer a molecule from bulk solution to the adsorption region. The Polanyi potential differences with the concentration according to [33]:

$$
\varepsilon=R T \ln \left(1+\frac{1}{C_{e}}\right)
$$

where $\mathrm{R}$ is the ideal gas constant and $\mathrm{T}$ is the temperature $(\mathrm{K})$. A linear correlation is manufactured by plotting $\ln$ qe versus $\varepsilon 2$ (shown in Table 2), indicating that TC adsorption also obeys the $\mathrm{D}-\mathrm{R}$ equation. The adsorption energy for TC adsorption can be determined by:

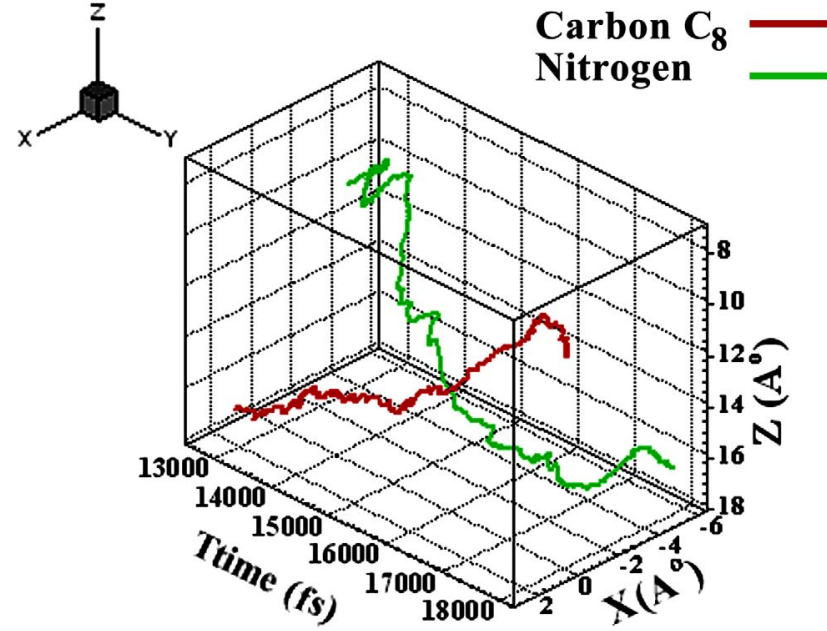

Figure 9. Variation of $z$ and $x$ vs. time. doi:10.1371/journal.pone.0079254.g009

$$
E=(-2 K)^{-1 / 2}
$$

The values of the adsorption energy were estimated as $1.83,1.69$ and $1.4 \mathrm{~kJ} / \mathrm{mol}$, at $298,303,308 \mathrm{~K}$ respectively, indicating that the values lie within the energy range of physical adsorption, i.e., $<8 \mathrm{~kJ} / \mathrm{mol}$.

\section{Thermodynamic Studies}

The sorption manners of different concentrations of TC onto GO were critically explored at 298, 303, 308, 310 and $313 \mathrm{~K}$, respectively. Thermodynamic parameters were computed from following equations:

$$
\Delta G^{\circ}=-R T \ln K_{c}
$$

where $\mathrm{R}$ is the universal gas constant $(8.314 \mathrm{~kJ} / \mathrm{mol} \mathrm{K}), \mathrm{T}$ is the temperature $(\mathrm{K})$ and $\mathrm{K}_{\mathrm{c}}$ is the distribution coefficient. Gibbs free energy change of adsorption $\left(\Delta \mathrm{G}^{\circ}\right)$ was calculated using $\ln \mathrm{K}_{\mathrm{c}}$ values for different temperatures. The $\mathrm{K}_{\mathrm{c}}$ value was calculated using following equation [34]:

$$
K_{c}=\frac{q_{e}}{C_{e}}
$$

where $\mathrm{Ce}$ is the equilibrium concentration of $\mathrm{TC}$ and qe is the amount of TC adsorbed per unit weight of $\mathrm{GO}$ at equilibrium concentration $(\mathrm{mg} / \mathrm{g})$. The enthalpy change $\left(\Delta \mathrm{H}^{\circ}\right)$ and entropy change $\left(\Delta \mathrm{S}^{\circ}\right)$ of adsorption were estimated from the following equation [35]:

$$
\Delta G^{\circ}=\Delta H^{\circ}-T \Delta S^{\circ}
$$

According to Eq. $15, \Delta \mathrm{H}^{\circ}$ and $\Delta \mathrm{S}^{\circ}$ factors can be calculated from the slope and intercept of the plot of $\Delta \mathrm{G}^{\circ}$ against $\mathrm{T}$, respectively. The thermodynamic parameters were shortened in Table 3 . The positive values of $\Delta \mathrm{H}^{\circ}$ and the negative values of $\Delta \mathrm{G}^{\circ}$ show the endothermic and spontaneous nature of sorption process. 


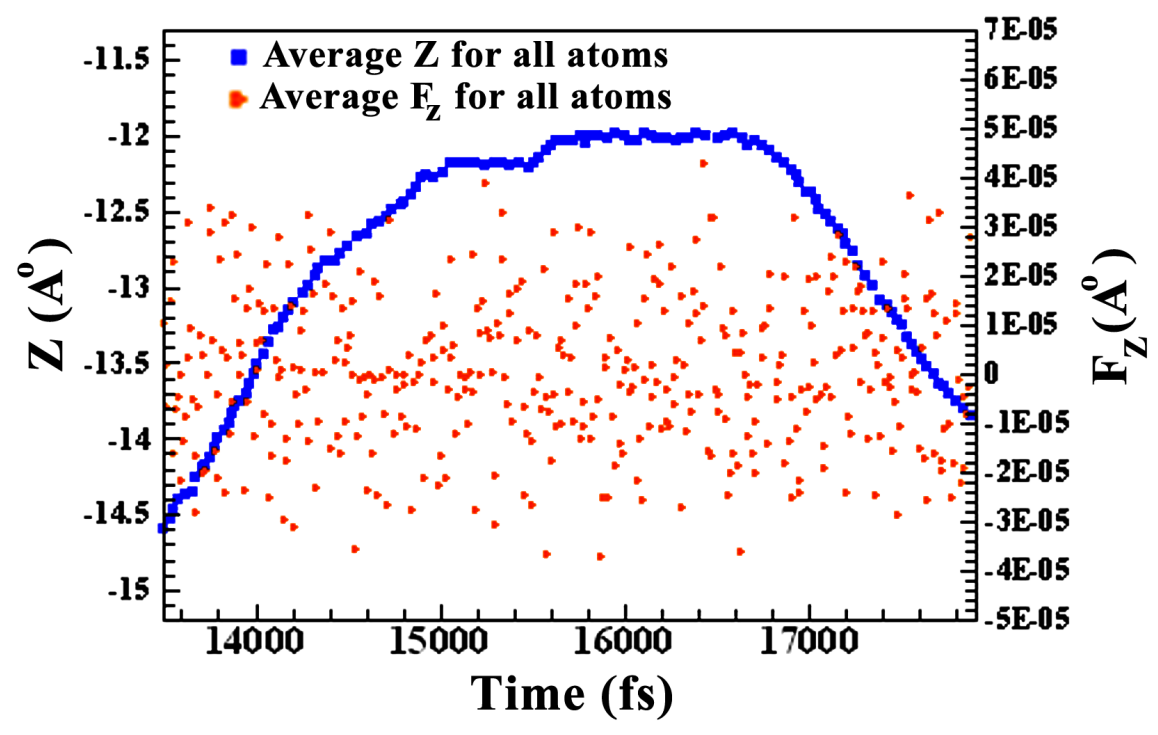

Figure 10. Variation of resultant force in the $z$ direction $v s$, time. doi:10.1371/journal.pone.0079254.g010

\section{Electrochemical Studies}

The voltammetric response of graphene oxide/glassy carbon electrode $(\mathrm{GO} / \mathrm{GCE})$ in the absence and presence of tetracycline (1.0 mM in phosphate buffer, $0.1 \mathrm{M}, \mathrm{pH} 7.0$, scan rate of $50.0 \mathrm{mV} / \mathrm{s}$ ) is shown in Fig. 7. The cyclic voltammetric behavior of the tetracycline evidenced one broad oxidation peak with the peak potential at Epa $=0.84 \mathrm{~V}$ during the anodic scan (Fig. 7a). No peaks were observed in the reverse scan, suggesting the irreversible nature of the oxidation process of tetracycline at the GO/GCE.

In the electrochemical investigations, useful information involving the electrochemical reaction mechanisms usually can be obtained from the potential scan rate. Therefore, the electrochemical behavior of tetracycline $(1.0 \mathrm{mM})$ was investigated at pH 7.0 and scan rate from 25 to $400 \mathrm{mV} / \mathrm{s}$ by cyclic voltammetry (Fig. 7b). As shown in Fig. 7c, by increasing the scan rate from 25 to $400 \mathrm{mV} / \mathrm{s}$, a linear relationship was observed between the peak intensity Ipa and the scan rate $v$ (Fig. 7b), indicating that the oxidation of tetracycline at GO/GCE is an adsorption-controlled process. The effect of scan rate on peak current was also studied under the above conditions with a plot of $\log$ I (logarithm of peak current) vs. $\log v$ (logarithm of scan rate), giving a straight line with a slope of 0.91 (Fig. 7d). This value is close to the theoretical value of 1 , which is expected for an ideal reaction for the adsorption controlled electrodic process [36].

\section{Simulation}

The behavior of TC near the GO sheet was studied by Lammps code. GO was considered as $25 \times 25$ nanometer square sheet and $z=-5$ position with periodic boundary condition using the Adaptive Intermolecular Reactive Empirical Bond Order (AIREBO) potential. The AIREBO model is a function for calculating the potential energy of covalent bonds and the interatomic force. In this model, the total potential energy of system is a sum of nearest-neighbor pair interactions which depends not only on the distance between atoms but also on their local atomic environment. A parameterized bond order function was used to describe chemical pair bonded interactions. The adaptive intermolecular reactive bond order (AIREBO) potential, in which both the repulsive and attractive pair interaction functions are modified to fit bond properties, and the long-range atomic interactions and single bond torsional interactions are included [18]. The AIREBO model has been used in recent studies using numerical [19]. Center of TG is at the zero point of coordinate and force cut of radius is $10 \AA$. Temperature increases to $25^{\circ} \mathrm{C}$ after 1000 run step and steady state has been considered after $2 \times 10^{5}$ run step. It has been averaged over $\mathrm{z}$. Figure 8 shows variation of $\mathrm{z} v$ s. time for $\mathrm{C}_{8}$ (triangle symbol) and amino (circle symbol). It can be seen that the distance between TC (from the $\mathrm{C}_{8}$ side) and GO sheet decreases to $14400 \mathrm{fs}$. Then TC turns and goes close to GO sheet from the amino side. In this case the center of TC is $7 \AA$ far from GO sheet. The closest distances for the $\mathrm{C}_{8}$ and amino side are 2.6 and $5 \AA$ respectively. The curve with square symbol is $\mathrm{z}$ average across $\mathrm{TC}$ molecules (Fig. 8).

Variation of $\mathrm{x}$ and $\mathrm{z} v$ s. time has been shown in Fig. 9. 3D curves show a clear turning of TC. The resultant force in the $\mathrm{z}$ direction changes with time (Fig. 10). The triangle symbol implies absorption and repulsion force towards GO. Molecules with absorption force less than $15000 \mathrm{fs}$, and repulsion force greater than $18000 \mathrm{fs}$ are dominated which means that TC goes close to and far from GO sheet, and turns at time 15000-17000 fs since two forces are equal. These results are in agreement with Fig. 8. The simulation results are consistent with FTIR and UV results which approved the complex formation between GO and TC.

\section{Conclusion}

The adsorption behavior results show high adsorption efficiency of TC on GO. The adsorption mechanism is non-electrostatic dispersion and hydrophobic interaction between TG and GO. The ring structure in tetracycline molecule and the surface of the graphene oxide facilitate $\pi-\pi$ interaction between them. Cation $-\pi$ bonding was likely to happen between the amino group on the $\operatorname{ring} \mathrm{C}_{4}$ of tetracycline and $\mathrm{GO} \pi$-electron-rich structures. $\mathrm{GO}$ can effectively release $\mathrm{TC}$ in aqueous solution in wide range of $\mathrm{pH}$ from 2 to 10 . The percentage of TC release by GO can reach $99.8 \%$. Kinetic studies suggest that the equilibrium is achieved within only $15 \mathrm{~min}$ and the pseudo-second-order model is followed. The adsorption isotherms could be well fitted by the Langmuir adsorption isotherm equations with the maximum 
adsorption capacity of $322.43 \mathrm{mg} / \mathrm{g}$ (298 K) of TC on GO. The thermodynamic parameters imply that the adsorption is a spontaneous, endothermic and physisorption process.

Simulation studies show the presence of $\pi-\pi$ stacking interactions between tetracycline and graphene's surface. The closest distance between TC and GO is $6.2 \AA$. After $15000 \mathrm{fs}$ and where the distance between center of TC and GO sheet is $7 \AA$, TC starts to turn. After $17000 \mathrm{fs}$, the amine group side of TC is moving far from graphene surface to $5 \AA$ distance. Simulation results show that at any moment, some of the TC molecules are adsorbed and some of them are repulsed by graphene sheet which represent the

\section{References}

1. Namgung R, Zhang Y, Fang QL, Singha K, Lee HJ, et al. (2011) Multifunctional silica nanotubes for dual-modality gene delivery and MR imaging. Biomaterials 32: 3042-30521.

2. Singh V, Joung D, Zhai L, Das S, Khondaker SI, et al. (2011) Graphene based materials: Past, present and future. Prog Mater Sci 56: 1178-1271.

3. Li JL, Bao HC, Hou XL, Sun L, Wang XG, et al. (2012) Graphene oxide nanoparticles as a nonbleaching optical probe for two-photon luminescence imaging and cell therapy. Angew Chem Int Ed Engl 51: 1830-1834.

4. Park S, Lee KS, Bozoklu G, Weiwei C, Nguyen ST, et al. (2008) Graphene oxide papers modified by divalent ions-Enhancing mechanical properties via chemical cross-linking. ACS Nano 2: 572-578.

5. Dreyer DR, Park S, Bielawski CW, Ruoff RS (2009) The chemistry of graphene oxide, Chem Soc Rev 39: 228-240.

6. Margine ER, Bocquet ML, Blasé X (2008) Thermal stability of graphene and nanotube covalent functionalization. Nano Lett 8: 3315-3319.

7. Dikin DA, Stancovich S, Zimney EJ, Piner RD, Dommett GH, et al. (2007) Preparation and characterization of graphene oxide paper. Nature 448: 457460.

8. Zhang JL, Yang HJ, Shen GX, Cheng P, Zhang JY, et al. (2010) Biocompatibility of graphene oxide. Chem Commun, 46: 1112-1114.

9. Sun X, Liu Z, Welsher K, Robinson JT, Goodwin A, et al. (2008) Nanographene oxide for cellular imaging and drug delivery. Nano Res 1: 203-212.

10. Islam MM, Franco CD, Courtman DW, Bendeck MP (2003) A nonantibiotic chemically modified tetracycline (CMT-3) inhibits intimal thickening. Am J Pathol 163: 1557-1566.

11. Caroni ALPF, de Lima CRM, Pereira MR, Fonseca JLC (2012) Tetracycline adsorption on chitosan: A mechanistic description based on mass uptake and zeta potential measurements. Colloids Surf B: Biointerfaces 100: 222-228.

12. Castillo G, Criado S, Diaz M, Garcıa NA (2007) Riboflavin as a sensitizer in the photodegradation of tetracyclines. Kinetics, mechanism and microbiological implications. Dyes Pigments 72: 178-184.

13. Branham ML, Moyo T, Abdallah HMI, Masina P (2013) Tetracycline-ferrite nanocomposites formed via high-energy ball milling and the influence of milling conditions. Eur J Pharm Biopharm 83: 184-192.

14. Marcano DC, Kosynkin DV, Berlin JM, Sinitskii A, Sun Z, et al. (2010) Improved synthesis of graphene oxide. ACS Nano 4: 4806-4814.

15. Froehlich E, Mandeville JS, Jenning R, Sedaghat-Herati R, Tajmir-Riahi HA (2009) Dendrierms bind human serum albumin. J Phys Chem B 11: 6986-6993.

16. Gao Y, Li Y, Zhang L, Huang H, Hu J, et al. (2012) Adsorption and removal of tetracycline antibiotics from aqueous solution by graphene oxide. J Colloid Interface Sci 368: 540-546.

17. Wammer KH, Slattery MT, Stemig AM, Ditty JL (2011) Tetracycline photolysis in natural waters: Loss of antibacterial activity. Chemosphere 85: 1505-1510.

18. Brenner DW, Shendrova OA, Harrison JA, Stuart SJ, Ni B, et al. (2002) A second-generation reactive empirical bond order (REBO) potential energy expression for hydrocarbons. J Phys: Condens Matter 14: 783-802.

19. Van Duin ACT, Dasgupta S, Lorant F, Goddard WA (2001) ReaxFF: A reactive force field for hydrocarbons. J Phys Chem A 105: 9396-9409. equilibrium concentration $\left(\mathrm{C}_{\mathrm{e}}\right)$. TC molecules are in the mode of adsorption and desorption from graphene surface and the total energy of adsorption and desorption is equal to $-6800 \mathrm{~J}$.

\section{Author Contributions}

Conceived and designed the experiments: EEG FM GS HH SK ShN. Performed the experiments: EEG FM GS HH SK ShN. Analyzed the data: EEG FM GS HH SK ShN. Contributed reagents/materials/analysis tools: EEG FM GS HH SK ShN. Wrote the paper: EEG FM GS HH SK ShN.

20. Zhang L, Song X, Liu X, Yang L, Pan F, et al. (2011) Studies on the removal of tetracycline by multi-walled carbon nanotubes. Chem Eng J 178: 26-33.

21. Shen J, Li N, Shi M, Hu Y, Ye M (2010) Covalent synthesis of organophilic chemically functionalized graphene sheets. J Colloid Interface Sci 348: 377-383.

22. Brigante M, Schulz PC (2011) Remotion of the antibiotic tetracycline by titania and titania-silica composed materials. J Hazard Mater B 192: 1597-1608.

23. Zhao Y, Gu X, Gao S, Geng J, Wang X (2012) Adsorption of tetracycline (TC) onto montmorillonite: Cations and humic acid effects. Geoderma 183-184: $12-$ 18.

24. Domingues ZR, Cortés ME, Gomes TA, Diniz HF, Freitas CS, et al. (2004) Bioactive glass as a drug delivery system of tetracycline and tetracycline associated with b-cyclodextrin. Biomaterials 25: 327-333.

25. Liu P, Liu WJ, Jiang H, Chen JJ, Li WW, et al. (2012) Modification of bio-char derived from fast pyrolysis of biomass and its application in removal of tetracycline from aqueous solution. Bioresour Technol 121: 235-240.

26. Malkoc E (2006) Ni(II) removal from aqueous solutions using cone biomass of Thuja orientalis. J Hazard Mater B 137: 899-908.

27. Zhang P, Wang L (2010) Extended Langmuir equation for correlating multilayer adsorption equilibrium data. Separation and Purification Technology 70: 367371.

28. Schwaab M, Lemos LP, Pinto JC (2008) Optimum reference temperature for reparameterization of the Arrhenius equation. Part 2: Problems involving multiple reparameterizations. Chem Eng Sci 63: 2895-2906.

29. Chang YP, Ren CL, Qu JC, Chen XG (2012) Preparation and characterization of $\mathrm{Fe} 3 \mathrm{O} 4 /$ graphene nanocomposite and investigation of its adsorption performance for aniline and p-chloroaniline. Appl Surf Sci 261: 504-509.

30. Fan L, Luo C, Sun M, Li X, Qiu H (2013) Highly selective adsorption of lead ions by water-dispersible magnetic chitosan/graphene oxide composites. Colloids Surf B: Biointerfaces 103: 523-529.

31. Yang X, Li J, Wen T, Ren X, Huang Y, et al. (2013) Adsorption of naphthalene and its derivatives on magnetic graphene composites and the mechanism investigation. Colloids Surf A: Physicochemical and Engineering Aspects 422: $118-125$.

32. Ramesha GK, Kumara AV, Muralidhara HB, Sampath S (2011) Graphene and graphene oxide as effective adsorbents toward anionic and cationic dyes. J Colloid Interface Sci 361: 270-277.

33. Petrou AL (2012) The free energy of activation as the critical factor in geochemical processes. Chem Geol 308-309: 50-59.

34. Yao Y, Miao S, Liu S, Ma LP, Sun H, et al. (2012) Synthesis, characterization, and adsorption properties of magnetic Fe3O4@graphene nanocomposite. Chem Eng J 184: 326-332.

35. Song L, Wang S, Jiao C, Si X, Li Z, et al. (2012) Thermodynamics study of hydrogen storage materials. J Chem Thermodyn 46: 86-93.

36. Bagheri A, Hosseini H (2012) Electrochemistry of raloxifene on glassy carbon electrode and its determination in pharmaceutical formulations and human plasma. Bioelectrochemistry 88: 164-170. 